\title{
An Inexpensive and Novel Optical Scheme of Assessing Adulterants in Emulsions
}

\author{
Rajib Biswas $^{1, *}$ (D) , Pralay Kumar Karmakar ${ }^{2}$ (D) \\ Applied Optics and Photonics Laboratory, Department of Physics, Tezpur University, India \\ Astrophysical Plasma Lab, Department of Physics, Tezpur University, India \\ Correspondence: rajib@tezu.ernet.in;
}

Scopus Author ID 57202591766

Received: 5.05.2020; Revised: 28.05.2020; Accepted: 28.05.2020; Published: 1.06.2020

\begin{abstract}
An inexpensive way of polarimetric detection of urea as an adulterant in milk is reported. The novelty of the underlying experimental technique lies in its implementation of the Laurent halfshade polarimeter as the optical sensing unit. Different specific rotations are examined corresponding to varying concentrations of urea in milk. The experimental results are ascertained to go in excellent agreement with theoretical predictions. The detection setup is found to be cost-effective, user-friendly, and less time-consuming, as compared to conventional techniques, with a remarkable detection limit ( $0.4 \mathrm{mg} / \mathrm{ml})$.
\end{abstract}

Keywords: milk; polarimeter; specific rotation.

(C) 2020 by the authors. This article is an open-access article distributed under the terms and conditions of the Creative Commons Attribution (CC BY) license (https://creativecommons.org/licenses/by/4.0/).

\section{Introduction}

Milk, considered as an inevitable component of health nutrients spanning from infants to adults, is attained through various means. With rapid urbanization as well as a growing population, there is a decline of grazing fields for cattle [1-5]. The problem is again compounded by increasing demand for supply to meet the growing population. This leads to fraudulent steps taken up by producers and vendors to increase milk supply. They may either dilute or add unhygienic adulterants, but without altering the apparent color of milk. [1-10]. The common chemical adulterants, which have been reported to be prevalent in milk, are sodium hydroxide, formalin, hydrogen peroxide, cane sugar, starch, gelatine, synthetic dyes, soap detergents and urea [6, 11-14]. Among them, urea can be regarded as the frequently utilized adulterants used in raw milk. As per WHO (World Health Organisation) and FAO (Food and Agriculture Organization of the United Nations) guidelines, the permissible limit of urea in milk is around $50 \mathrm{mg} / 100 \mathrm{ml}$ [11-12]. However, every nation has fixed its standard of urea proportion and other elements in milk. For instance, nodal govt. agency, such as the Food Safety and Standards Authority of India, has set the permissible limit of urea content in milk at $70 \mathrm{mg} / 100 \mathrm{ml}$ [11]. When this limit is exceeded, urea becomes an adulterant in milk, losing its' natural constituent value. This increase in concentration generally occurs in two ways. The natural occurrence is caused by feeding cows highly nitrogen-rich compounds, which eventually percolates to raw milk [29-34]. On the contrary, urea, caustic soda, formalin and detergents, etc. are blended so that it does not alter the true color of milk. However, these immiscible items incur a total imbalance in the nutritional ingredients of milk, thereby raising the adulteration levels. Regular intake of urea contaminated milk may lead to several health 
hazards, such as heart diseases, kidney diseases, poor eyesight, and loss of memory [11-14]. In order to keep an eye on concentration levels of urea, although preventive measures are taken up by authorities, however, scrupulous mixing of urea cannot be deterred totally.

Towards the detection of concentration levels of adulterating species, there are some established direct or indirect methodologies [35-49]. The term indirect refers to the enzymatic degradation of urea before detection. Direct procedures have been defined as those resulting in a colored product, which indicates the presence of urea. However, this method cannot give quantitative measurements. Various analytical techniques available to determine urea are based on colorimetric or chromatographic methods, which consume a longer time duration considerably to get the species analyzed. These techniques are, however, too tedious and expensive to be used. Although lacking the inherent selectivity of the colorimetric technique, UV absorbance measurement also offers a convenient method of detection when coupled with chromatographic or electro-phonetic separation. Infrared spectrometry is another technique for the determination of urea, which may be particularly suitable for dairy industry research, where this technique is already employed for the analysis of milk for fats and proteins. However, multivariate-analysis techniques are required to estimate the contribution of urea from the overlapping absorption bands of other components. Of late, surface-enhanced Raman Spectroscopy and voltaperometric discrimination have been applied for the detection of contamination [12-17, 19-21]. However, again, they are delimited by efficient signal control and distinction. Precisely, no single technique is much versatile to provide satisfactory results in all the significant domains. Besides, all these analyses mentioned above procedures are not only expensive but also require trained personnel. As such, there is an impending need for a cost-effective technique which can eliminate all the lacunae, encountered by these sophisticated protocols. This motivates us to take up this endeavor to come up with a robust, yet cost-effective technique. It will be no exaggeration to claim that this is the first proof-ofconcept of implementing this technique towards the determination of contaminating urea in milk.

To accomplish this task, we have used a laboratory-grade Laurent half-shade polarimeter [LHP] in order to assess the concentration of urea in milk. With the varying concentration of adulterating species, we have quantitatively estimated adulteration content from modulated intensity on optical rotation, as invoked by the cost-effective apparatus.

\section{Experimental Details}

The experiment has been executed with a very common lab-set up known as LHP, schematic of which is depicted in Figure 1.

LHP is advantageous in many ways as compared to its existing counter-partners for concurrent polarimetric applications. For instance, the other polarimeters, although having a high sensitivity, suffer from inherent operating conditions. In the existing polarimeter, it is essential to obtain a point of minimum and maximum intensity, which is itself cumbersome and may vary with operators' perception. This puts a restriction on the robust measurement of optical rotation. The used polarimeter, in our case, is devoid of such inherent conditions. Instead of finding maxima or minima, one proceeds for exploring the position of equal brightness or darkness. It thus alleviates the need for intensity mapping. Due to the identical absorptive nature of the quartz and glass elements of LHP, the darkness and brightness are equally formed. Besides, the sensitivity of LHP [0.05 degree] is remarkably at par with available designs, qualifying estimation of the concentration of urea $[\sim \mathrm{mg} / \mathrm{ml}]$ in milk [30-49]. 
We have utilized a standard protocol. Accordingly, we have filled the tube $\mathrm{T}$ of the polarimeter with millipore water initially, which was further accompanied by an adjustment of the analyzer to yield equal darkness in the two halves. The position of the analyzer is noted with the help of a scale. Afterward, the polarimeter tube is filled with the analyte (Milk solution) of known concentration. Then, we have again made adjustments like the initial stage of the analyzer to attain the point of identical darkness. The position of the analyzer is again noted. The difference between the two readings will provide the angle of rotation $\theta$. Let us assume that the length of the tube and concentration of the analyte to be $L$ and $C$, respectively. In such a case, the following expression links the specific rotation $S$ to $L$ and $C$,

$$
[S]_{\lambda}^{t}=\frac{\theta}{L C} \text {. }
$$

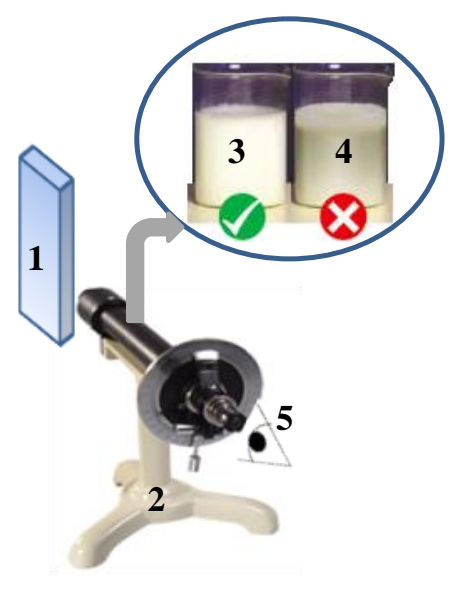

1-Light Source 2-Laurent's Half Shade Polarimeter

3-Pure Milk 4-Adulterant Milk 5-Viewer

Figure 1. Schematic of polarimetric setup.

Again, a linearly polarized light (with amplitude ) can be considered to be the sum of two linearly polarized waves. The first one is the wave polarized in the transmission plane propagating (with amplitude $\sqrt{I_{o}} \cos \theta$ ) through the polarizer without any change. On the other hand, the second wave is fully absorbed (with remaining no amplitude) in the transmission plane. As such, applying Malus' Law [34-35, 36-37], the normalized resultant light intensity can be expressed as $I / I_{0}=\cos ^{2} \theta$, where $I_{0}$ denotes the intensity with the pure analyte (milk with no urea-adulteration), and I denote intensity at different concentrations (milk with urea-adulteration). As a consequence, it should provide an alternative test-bed for reliability check-up of the experimental results being discussed in the following section.

$3 \mathrm{ml}$ of mercuric iodide (prepared by dissolving $3.32 \mathrm{~g}$ potassium iodide and $1.35 \mathrm{~g}$ mercuric chloride in $20 \mathrm{ml}$ glacial acetic acid and $64 \mathrm{ml}$ of distilled water) were added to $6 \mathrm{ml}$ milk sample. After $15 \mathrm{~min}$, the contents were centrifuged. The optical rotation of filtrate was measured in a polarimeter at room temperature using a $1 \mathrm{dm}$ polarimeter tube at $589.3 \mathrm{~nm}$ (sodium D line).

\section{Results and Discussion}

We have successfully found out the concentrations of adulterating urea in milk using a widespread laboratory setup. We have added known concentrations of adulterant in pure milk, and each time, the optical rotation is estimated. In general, pure milk is not an optically active substance. In order to make it optically active, the procedure discussed above is followed. With 
a constant light source under ambient conditions, we have varied the concentrations of urea in milk. The concentrations as added have been $0.01 \%, 0.02 \%, 0.04 \%, 0.08 \%, 0.1 \%, 0.2 \%, 0.4 \%$, $0.6 \%, 0.8 \%, 1 \%, 2 \%, 3 \%, 4 \%$. We have computed the mean optical rotation of a pure sample

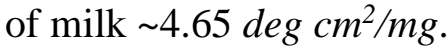

In general, the adulterant urea does not reveal optical rotation. However, when added as an adulterant in milk, the optical rotations become sensibly detectable. Fig. 2 depicts the number of optical rotations corresponding to the different concentrations of urea in milk. As seen in Fig. 2, it is evident that optical rotation decreases with an increase in the concentration of solute (urea) in solution (milk).

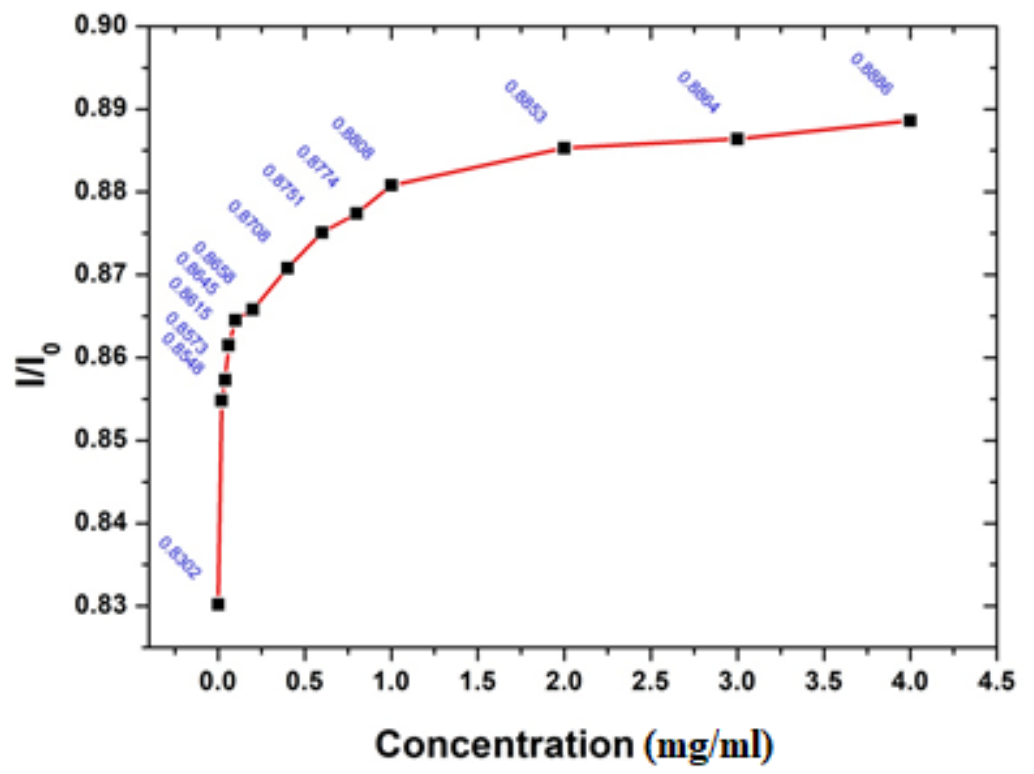

Figure 2. Specific rotation vs. concentration.

In other words, optical activity decreases with the addition of urea concentration. In similitude to the attained profile, we are encouraged to have a look at the intensity distribution. Following Malus' law [35], we have plotted the intensity profile against concentration, as depicted in Fig. 3.

The relative intensity profile shows a similar trend, as observed in Fig. 2. For a higher level of concentrations of adulterants, we can observe that the relative change in intensity gradually increases. When the urea content in milk is high, the relative change in intensity rises sharply. When the optical rotation is correlated with it, we find an interesting hint that intensity increases with a higher value of concentrations as the optical rotation declines. Both Figs. 2-3 is strong evidence of the fact that polarimetric detection of adulteration can be sensed in two domains, viz., optical rotation and relative change in intensity level as well.

The detected adulterant, Urea $\left[\mathrm{CO}\left(\mathrm{NH}_{2}\right)_{2}\right]$, contains two amine groups, $\mathrm{NH}_{2}$. It is a natural constituent of milk. As we use a plane polarised light source for getting the optical rotation via varying concentration levels of urea, both the optical rotation as well as the intensity of propagating light start changing. Being a polar molecule, it has an inherent dipole moment of its own. Due to electromagnetic interaction of the impinged optical beam with urea, there is a plausible orientational polarisation of inherent constitutive dipoles. When we enhance the concentration of urea, there is a non-zero net impact in the balanced orientational polarisation, which yields a declining trend in optical rotation. Meanwhile, it also influences the intensity of light, as depicted in Fig. 3. As evidenced in Fig. 2, our proposed system is found to have a remarkable sensing limit of $0.4 \mathrm{mg} / \mathrm{ml}$. As per the guidelines of FSSAI, it should be 
around $70 \mathrm{mg} / 100 \mathrm{ml}$. This matches well within the perceivable limit of the detection of urea. In terms of the actual cost, the whole setup amounts merely to $\$ 50$.

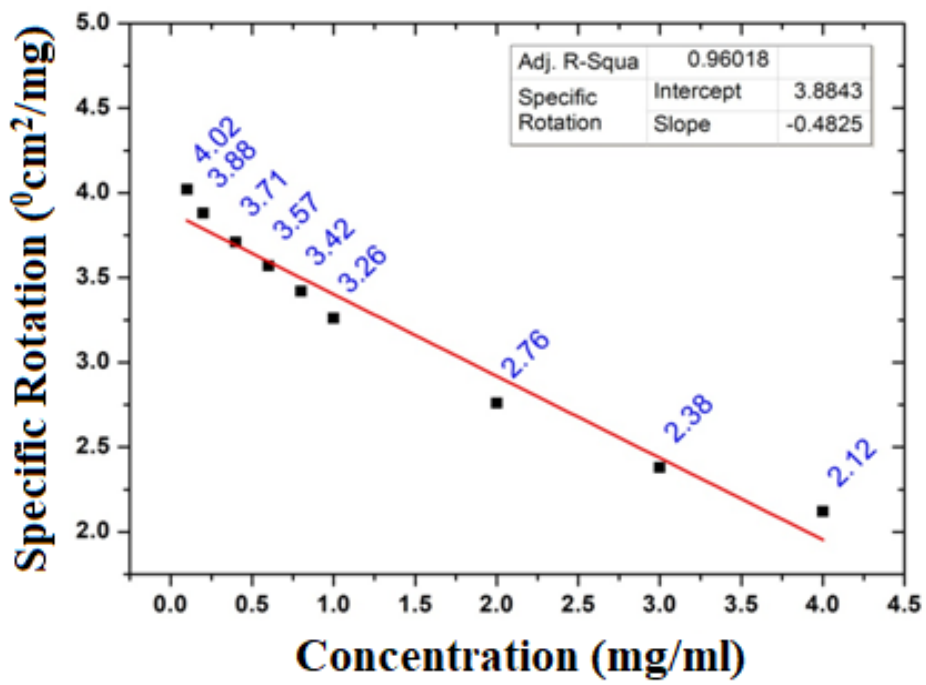

Figure 3. Relative intensity $\left(I / I_{0}\right)$ vs. concentration $(\mathrm{mg} / \mathrm{ml})$.

The attained results are in good agreement with the theoretical prediction. In the context of consumption of time, this procedure is faster as compared to other sophisticated instruments such as HPLC, and Plasma assisted technologies, etc. The results derived from this proposed detection mechanism possesses a good degree of repeatability and reproducibility.

\section{Conclusions}

A polarimetric sensing technique to detect milk adulteration with excellent sensitivity has been summarily reported. The polarimetric response corresponding to milk adulteration is found to have good conformity with our theoretical predictions. As the concentration of adulterant in the form of urea in milk is increased, the values of optical rotation show a gradual decline towards the baseline. This scheme is found to have good linearity corresponding to the measurable optical range. It can be well asserted that LHP can be effectively used as an alternative means for the detection of adulterant in milk. This can also be extensively treated as a substitutive detection device for the degree of milk purity and identical edible (drinkable) emulsions in the future.

\section{Funding}

This research received no external funding.

\section{Acknowledgments}

This research has no acknowledgment.

\section{Conflicts of Interest}

The authors declare no conflict of interest.

\section{References}

1. Singh, A.; Sharma, J.; Bhatt, S.R. Detection of ill-effects of urea adulterated milk in Varanasi. Food Science Research Journal 2011, 2, 46-49. 
2. Das, S.; Sivaramakrishna, M.; Biswas, K.; Goswami, B. Performance study of a constant phase angle based impedance sensor to detect milk adulteration, Sensors and Actuators A: Physical 2011, 167, 273-278, https://doi.org/10.1016/j.sna.2011.02.041.

3. Zhang, X.F; Zou, M.Q.; Qi, X.H.; Liu, F.; Zhu, X.H.; Zhao, B.H. Detection of melamine in liquid milk using surface-enhanced Raman scattering spectroscopy. J. Raman Spectrosc 2010, 41, 1655-1660, https://doi.org/10.1371/journal.pone.0107770.

4. Santos, P.M.; Pereira-Filho, E.R.; Rodriguez-Saona, L.E. Application of Hand-Held and Portable Infrared Spectrometers in Bovine Milk Analysis. J Agri Food Chem 2013a, 61, 1205-1211, https://doi.org/10.1021/jf303814g.

5. Biswas, R.; Karmakar, P.K. A facile technique of sensing adulteration in emulsion: a road to safety. Ergonomics International Journal 2019, 3, https://doi.org/10.23880/eoij-16000218.

6. Mudgil, D.; Barak, S. Synthetic milk: a threat to Indian dairy industry. Carpathian J Food Sci Technol 2013 5: 64- 68 .

7. Dai, X.; Zhao, Y.; Li, M.; Fang, X.; Li, X.; Li, H.; Xu, B. Determination of urea in milk by liquid chromatography-isotope dilution mass spectrometry. Analytical Letters 2013 45, 1557-1565, https://doi.org/10.1080/00032719.2012.677779.

8. Banupriya, P.C.R.S.; Supriya, T.V.; Varshitha, V. Comparison of different methods used for detection of urea in milk by quantification of ammonia. Int J Adv Res Elect, Electron Instrum Eng 2014, 3,7858-7863.

9. Arvind Singh, G.C.; Aggarwal, A.; Kumar, P. Adulteration Detection in Milk. Res News For U (RNFU) 2012, 5, 52.

10. Nascimento, C.F.; Santos, P.M.; Pereira-Filho, E.R.; Rocha, F.R.P. Recent Advances on Determination of Milk Adulterants. Food Chemistry 2017, 221, 1232-1244, https://doi.org/10.1016/j.foodchem.2016.11.034.

11. Poonia, A.; Jha, A.; Sharma, R.; Singh, H.B.; Rai, A.K. \& Sharma, N. Detection of adulteration in milk: A review. Int. J. Dairy Technology 2017, 70, 23-42, https://doi.org/10.1111/1471-0307.12274.

12. Tian, H.; Zheng, N.; Wang, W.; Cheng, J.; Li, S.; Zhang, Y.; Wang, J. Integrated Metabolomics Study of the Milk of Heat-stressed Lactating Dairy Cows. Scientific Reports 2016, 6, https://doi.org/10.1038/srep24208.

13. Kowsar, R.; Iranshahi, V.N.; Sadeghi, N.; Riasi, A.; Miyamoto, A. An autoregressive logistic model to predict the reciprocal effects of oviductal fluid components on in vitro spermophagy by neutrophils in cattle. Scientific Reports 2017, 7, https://doi.org/10.1038/s41598-017-04841-z.

14. Hilding-Ohlsson, A.; Fauerbach, J.A.; Sacco, N.J.; Bonetto, M.C.; Cortón, E. Voltamperometric discrimination of urea and melamine adulterated skimmed milk powder. Sensors (Basel) 2012, 12, 1222012234, https://doi.org/10.3390/s120912220.

15. Trbović, D.; Petronijević, R.; Đorđević, V. Chromatography methods and chemometrics for determination of milk fat adulterants. IOP Conf. Series: Earth and Environmental Science 2017, 85, https://doi.org/10.1088/1755-1315/85/1/012025.

16. Gunnery, K.S. Additives in milk and their detection. Ind. Dairyman 1979, 39, 665-669.

17. Paul, P.S.; Simon, S.W.; Lim, K.F. Analytical methodology for the determination of urea: current practice and future trends. Trends in Analytical Chemistry, 2002, 21, 389-400, https://doi.org/10.1016/S01659936(02)00507-1.

18. Gutierrez, M.; Alegret, S.; Valle, M. Potentiometric bioelectronic tongue for the analysis of urea and alkaline ions in clinical samples. Biosensor \& Bio electron 2007, 22, 2171-2178, https://doi.org/10.1016/j.bios.2006.10.007.

19. Spenser, K.; Clin, A. Analytical reviews in clinical biochemistry: the estimation of creatinine. Biochem 1986, 23, https://doi.org/10.1177/000456328602300101.

20. Abdel, L.M.S.; Guibault, G.G. Fluorometric determination of urea by flow injection analysis, J. Biotechnol.; 14, 53, 1990.

21. Jenkins, D.M.; Delwiche, M.J.; DePeters, E.J.; BonDurant, R.H. Refinement of the Pressure Assay for Milk Urea Nitrogen. Journal of Dairy Science 2000, 83, 2042-2048, https://doi.org/10.3168/jds.S00220302(00)75085-5.

22. Verma, N.; Singh, M. A disposable microbial based biosensor for quality control in milk. Biosensors and Bioelectronics 2003, 18, 1219-1224, https://doi.org/10.1016/S0956-5663(03)00085-X.

23. Renny, E.F.; Daniel, D.K.; Krastanov, A.I, Zachariah, C.A.; Elizabeth, R. Enzyme based sensor for detection of urea in milk. Biotechnol.Biotechnol. Eq 2005, 19, 198-201, https://doi.org/10.1080/13102818.2005.10817216.

24. Luong, J.H.T.; Bouvrette, P.; Male, K.B. Developments and applications of biosensors in food analysis. Trends in Biotechnology 1997, 15, 369-377, https://doi.org/10.1016/S0167-7799(97)01071-8.

25. Singh, M.; Verma, N.; Garg, A.K.; Redhu, N. Urea biosensors. Sens.\& Act. B: Chem 2008, 134, 345, https://doi.org/ 10.1016/j.snb.2008.04.025.

26. Jonker, J.S.; Kohn, R.A.; Eradman, R.A. Using milk urea nitrogen to predict nitrogen excretion and utilization efficiency in lactating dairy cows. J. Dairy Sci. 1998, 81, 2681, https://doi.org/10.3168/jds.s00220302(98)75825-4. 
27. Trivedi, U.B.; Lakshminarayana, D.; Kothari, I.L.; Patel, N.G.; Kapse, H.N.; Makhija, K.K.; Patel, P.B.; Panchal, C.J. Potentiometric biosensor for urea determination in milk. Sensors and Actuators B: Chemical 2009, 140, 260-266, https://doi.org/10.1016/j.snb.2009.04.022.

28. Butler, W.R.; Calaman, J.J.; Beam, S.W. Plasma and milk urea nitrogen in relation to pregnancy rate in lactating dairy cattle, J. Anim. Sci. 1996, 74, 858-865, https://doi.org/10.2527/1996.744858x.

29. Kavitha, P.; Bector, B.S.; Sharma, V. Urea content of milk of Murrah breed of buffaloes. Buffalo Newsletter 2001, 16, 10-12.

30. www.indosawedu.com/laurents-half-shade-polarimeter.php[ Accessed on 15/05/2019]

31. DePeters, E.J.; Ferguson, J.D. Nonprotein nitrogen and protein distribution in the milk of cows. J. Dairy Sci 1992, 75, 3192.-3209, https://doi.org/10.3168/jds.S0022-0302(92)78085-0.

32. Butler, R.W.; Calaman, J.J.; Beam, S.W. Plasma and milk urea nitrogen in relation to pregnancy rate in lactating dairy cattle. J. Anim. Sci. 1996, 74, https://doi.org/10.2527/1996.744858x.

33. Larson, S.F.; Butler, W.R.; Currie, W.B. Reduced fertility associated with low progesterone postbreeding and increased milk urea nitrogen in lactating cows. J. Dairy Sci. 1997, 80, 1288-1295, https://doi.org/10.3168/jds.S0022-0302(97)76058-2.

34. Lakard, B.; Herlem, G.; Lakard, S.; Antoniou, A.; Fahys, B. Urea potentiometric biosensor based on modified electrodes with urease immobilized on polyethylenimine films. Biosens \& Bioelectron 2004, 19, 1641-1647, https://doi.org/10.1016/j.bios.2003.12.035.

35. Brukner, C.; Zeilinger, A. Malus' law and quantum information. Acta Physica Slovaca 1999, 49, 647-652.

36. Mohamed H.; Abd El-Salam , Safinaz El-Shibiny, Hardness of high protein nutrition bars based on milk protein concentrates:a review. Biointerface Research in Applied Chemistry 2020, 10, 4914-4921, https://doi.org/10.33263/BRIAC101914921.

37. Haghani-Haghighi, H.; Mortazavian, A.M.; Hosseini, H.; Mohammadi, A.; Shojaee-Aliabadi, S.; KhosraviDarani, K.; Khorshidian, N. Method validation and determination of hydroxymethyl furfural (HMF) and furosine as indicators to recognize adulterated cow's pasteurized and sterilized milks made by partial reconstitution of skim milk powder. Biointerface Res. Appl. Chem. 2019, 9, https://doi.org/10.33263/BRIAC92.842848.

38. Punvichai, T.; Pioch, D. Co-valorization of agro-industry by-products: effect of citrus oil on the quality of soap derived from palm fatty acid distillate and spent bleaching clay. Letters in App. NanoBio 2019, 8, 571575, https://doi.org/10.33263/LIANBS83.571575.

39. Biswas, R.; Nath, P. Sensitivity analysis of two-fiber optic sensors. Indian Journal of Physics 2014, 88, 1105-1110, https://doi.org/10.1007/s12648-014-0513-7.

40. Paul, D.; Biswas, R. Highly sensitive LSPR based photonic crystal fiber sensor with embodiment of nanospheres in different material domain. Optics and Laser Technology 2018, 101, 379-387, https://doi.org/10.1016/j.optlastec.2017.11.040.

41. Baruah, B.S; Biswas, R. Selective detection of arsenic (III) based on colorimetric approach in aqueous medium using functionalised gold nanoparticles unit. Material Research Express 2018, 5,1, https://doi.org/10.1088/2053-1591/aaa661.

42. Paul, D.; Biswas, R. Facile fabrication of sensing setup for size detection of nanoparticles. IEEE Transactions on Nanotechnology 2018, 17, 596-602, https://doi.org/10.1109/TNANO.2018.2806306.

43. Baruah, B.S.; Biswas, R. Localized surface plasmon resonance based U -shaped optical fiber probe for the detection of $\mathrm{Pb} 2+$ in aqueous medium. Sensors and Actuators B Chemical 2018, 276, 89-94, https://doi.org/10.1016/j.snb.2018.08.086.

44. Baruah, B.S.; Biswas, R. An optical fiber based surface plasmon resonance technique for sensing of lead ions: A toxic water pollutant. Optical Fiber Technology 2018, 46,152-156, https://doi.org/ 10.1016/j.yofte.2018.10.007.

45. Baruah, B.S.; Biswas, R.; Deb, P. A green colorimetric approach towards detection of arsenic (III): a pervasive environmental pollutant. Optics and Laser Technology 2019, 111, 825-829, https://doi.org/10.1016/j.optlastec.2018.09.023.

46. Baruah, B.S; Biswas, R. Mangifera indica leaf extract mediated gold nanoparticles: a novel platform for sensing of As(III) IEEE Sensors Letter 2019, 3, https://doi.org/10.1109/LSENS.2019.2894419.

47. Biswas, R. Adulteration in milk: A growing concern, Journal of Dairy and Veterinary Sciences. 2019, 9, 12, https://doi.org/10.19080/JDVS.2019.09.555751.

48. Boruah, B.S.; Daimari, N.K.; Biswas, R. Functionalized silver nanoparticles as an effective medium towards trace determination of arsenic (III) in aqueous solution. Results in Physics 2019, 12, 2061-2065. https://doi.org/10.1016/j.rinp.2019.02.044.

49. Biswas, R. Hetero Core Arrangement of Optical Fibers as an effective tool for different sensing applications. COJ Elec. Communicat 2019, 1, 5, https://doi.org/10.31031/COJEC2019.01.000523. 